\title{
Spring Loading Mechanism Device
}

National Cancer Institute

\section{Source}

National Cancer Institute. Spring Loading Mechanism Device. NCI Thesaurus. Code C50288.

A device that uses a spring to deliver something into a device or system. 